\title{
ROS Scavenger Decreases Basal Perfusion Pressure, Vasoconstriction and NO Synthase Activity in Pulmonary Circulation During Pulmonary Microembolism
}

\author{
R. MIZERA ${ }^{1,2}$, D. HODYC ${ }^{1}$, J. HERGET ${ }^{1}$ \\ ${ }^{1}$ Department of Physiology, Second Medical School, Charles University in Prague, Prague, Czech \\ Republic, ${ }^{2}$ Traumatology-Orthopedic Center, Regional Hospital Liberec, Liberec, Czech Republic
}

Received September 15, 2014

Accepted November 28, 2014

On-line March 24, 2015

\section{Summary}

Two mechanisms contribute in the development of pulmonary hypertension in pulmonary embolism (PE) - obstruction of pulmonary blood vessels and vasoconstriction. We hypothesize that hypoxia, increased shear stress and/or activation of gathered leukocytes in the PE may cause a release of reactive oxygen species (ROS). Therefore our aim was to determine the influence of the ROS scavenger Tempol on pulmonary hypertension and to describe NO synthase activity and production of NO oxidative products (NOx) after PE. In general anesthesia sephadex microspheres suspended in PSS were applied in right jugular vein as the pulmonary microembolism. Than we measured in isolated salt solution-perfused lungs the changes in perfusion pressure, activity of NO synthase and NOx plasma concentration in 7 groups of rats: $C$ : control group $(n=5)$, $C N: \mathrm{C}+$ sodium nitroprusside $(\mathrm{SN})(\mathrm{n}=5), E N: \mathrm{PE}+\mathrm{SN}(\mathrm{n}=5)$, ETN: Tempol + PE + SN $(n=5), C L: C+$ L-NAME $(n=5), E L: P E+$ L-NAME $(n=5)$, ETL: Tempol + PE + L-NAME $(n=5)$. Tempol was applied intraperitoneally before $\mathrm{PE}$. Animals that received Tempol (groups TN, TL) had significantly lower basal perfusion pressure than those which did not receive Tempol (EN, EL). Overall we measured a higher decrease of perfusion pressure than in the control group (C) after application of SN. Administration of L-NAME after PE (EL) increased the pressure more than in the control group (NL). NOx concentration was higher after PE. We found that preventive administration of Tempol decreases the increase in perfusion pressure after PE. PE increased NO release and concentration of NOx.

\section{Key words}

ROS scavenger • Pulmonary hypertension • Pulmonary embolism - Nitric oxide • Free radicals

\section{Corresponding author}

R. Mizera, Traumatologicko-ortopedické centrum KNL a.S., Husova 10, 46063 Liberec 1, Czech Republic. E-mail: roman.mizera@nemlib.cz

\section{Introduction}

Acute pulmonary embolism (PE) is a serious condition with an incidence of 20/1000 per year and is the third most common cause of death from cardiovascular disease after heart attacks and strokes in Europe. It is the most serious post-operative complication, particularly after long bone and joint surgeries. Pulmonary embolism is a significant cause of mortality and morbidity in hospitalized patients (10\% deaths during hospitalization) (Torbicki et al. 2008).

Successive pulmonary embolism which develops for a longer time leads to an increase in pulmonary vessel resistance, pulmonary hypertension and chronic right side heart failure.

There are two important mechanisms in the development of pulmonary hypertension after PE obstruction of pulmonary vessels by the embolus and vasoconstriction. Our hypothesis is that radical substances released in the lungs after PE may participate in some cases of PE induced increase of vascular resistance. Hypoxia, increased shear stress and activation of gathered leukocytes may cause the release of reactive oxygen species (ROS). ROS may be responsible for pulmonary vasoconstriction after PE (Stratmann and Gregory 2003). 
Therapy of PE is based mainly on the release of the obstruction by thrombus. The first choice of therapy is tPA thrombolysis combined with heparin anticoagulation. In certain cases a surgical method embolectomy - is indicated (Torbicki et al. 2008). Though experiments with vasodilatation by NO inhalation or by Sildenafil have been performed (TanusSantos et al. 1999, Dias-Junior et al. 2010), the vasodilatory therapy of PE induced pulmonary hypertension has not been implemented in clinical practice. Experimental evidence indicates that models of PE in laboratory animals are accompanied by oxidant stress of lung tissue (Dias-Junior et al. 2010). The key oxygen radical present in various types of lung injury including PE is superoxide.

In our experiments we used Tempol (4 hydroxy2, 2, 6, 6-tetramethylpiperidin-1-oxyl), which acts as a superoxide dismutase mimetics, for vasodilatation after experimental lung microembolism. Superoxide dismutase decreases the level of superoxide. In the presence of NO and superoxide these substances readily combine, yielding the biologically very reactive peroxynitrite.

In the present study we questioned the hypothesis that superoxide participates in lung vasoconstriction after pulmonary microembolism by Sephadex particles. In the first part of our study we focused on changes in perfusion pressure and the presence of vasoconstriction after PE with preventive application of Tempol. The second part describes observed changes in NO synthase activity and production of NO metabolic products after PE.

\section{Methods}

We used 30 male Wistar rats (aged 7-8 weeks, weight $240 \pm 20 \mathrm{~g}$ ). Work with animals was performed in accordance with European Community guidelines and US
National Institute of Health guidelines for the use of experimental animals. All parts of the experiment were approved by the Commission for Work with Laboratory Animals of the Second Medical School, Charles University in Prague.

\section{Pulmonary microembolism}

The right internal jugular vein was dissected in general anesthesia using a $40 \mathrm{mg} / \mathrm{kg}$ intraperitoneal injection of sodium thiopental. Then $0.2 \mathrm{ml}$ saline solution, which contained $320 \mathrm{mg}$ of Sephadex microspheres (G-26, Superfine per kilogram of body weight), was applied into the exposed jugular vein. The microspheres had been suspended in the PSS for $12 \mathrm{~h}$ before the application in order to enlarge their diameter by swelling (final particle size was $15-50 \mu \mathrm{m}$ ). The heartlung block was isolated twenty minutes after embolization and the preparation of isolated perfused lung was established (Herget et al. 1982).

\section{Preparation of isolated perfused rat lungs}

After thoracotomy, the lungs were ventilated by a normoxic gas mixture $\left(21 \% \mathrm{O}_{2}, 5 \% \mathrm{CO}_{2}, 74 \% \mathrm{~N}_{2}\right)$ by tracheal tube with the following ventilation parameters: PEEP $2 \mathrm{~cm} \mathrm{H}_{2} \mathrm{O}$, peak inspiratory pressure $10 \mathrm{~cm} \mathrm{H}_{2} \mathrm{O}$. An inflow cannula was inserted into the pulmonary artery and an outflow cannula into the left heart chamber, the lungs had been perfused with saline perfusate containing albumin $(4 \mathrm{~g} / 100 \mathrm{ml})$ at a constant flow rate $(4 \mathrm{ml} / \mathrm{min} / 100 \mathrm{~g})$. Isolated lungs were placed into a heated humid chamber. The outflow cannula was set up into a circle through a perfusate reservoir. The perfusion pressure was measured in the inflow cannula. After $20 \mathrm{~min}$ of stabilization, the changes in pressure corresponded to changes in the pulmonary vascular resistance (Herget and McMurtry 1987, Hampl and Herget 1990).

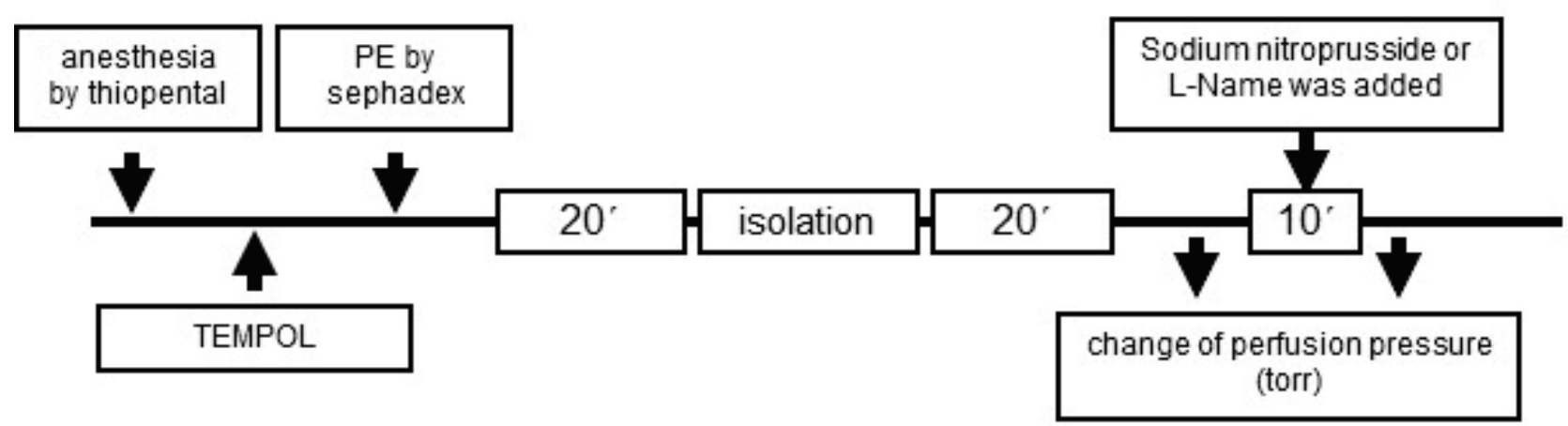

Fig. 1. Experimental protocol. 
Experimental protocol (Fig. 1)

\section{Basal perfusion pressure}

In this part of the experiment, animals were divided into 3 groups: $\mathrm{C}$ - control group ( $\mathrm{n}=10), \mathrm{E}-$ pulmonary embolization had been induced in the animals before the isolation of the lungs $(\mathrm{n}=10), \mathrm{ET}$ - similar as E but the animals had received $50 \mathrm{mg} / \mathrm{kg}$ of Tempol intraperitoneally before the embolization $(n=10)$. The basal perfusion pressure was measured after $20 \mathrm{~min}$ of stabilization.

\section{Presence of vasoconstriction}

Groups of animals were analogous to the previous part: $\mathrm{CN}$ - control group $(\mathrm{n}=5), \mathrm{EN}$ - pulmonary embolization had been performed on the animals before the isolation of the lungs $(n=5)$, ETN - the animals had received $50 \mathrm{mg} / \mathrm{kg}$ of Tempol intraperitoneally before the embolization $(n=5)$. The isolation of the lungs was followed by a stabilization period of $20 \mathrm{~min}$. After reading basal perfusion pressure, $0.5 \mathrm{ml} 20 \mu \mathrm{M}$ solution of sodium nitroprusside was added to the perfusate in each group and the basal perfusion pressure rate was noted after $10 \mathrm{~min}$. The difference between perfusion pressure before and after sodium nitroprusside reflects the pulmonary vascular tonus.

\section{NO release}

Rats were divided again into 3 groups: CL control group $(n=5), E L$ - pulmonary embolization had been performed on the animals before the isolation of the lungs $(\mathrm{n}=5)$, ETL - the animals had received $50 \mathrm{mg} / \mathrm{kg}$ of Tempol intraperitoneally before the embolization $(n=5)$. After the isolation of the lungs and stabilization, the L-NAME NO synthase inhibitor was added to the lung perfusate (final concentration $50 \mu \mathrm{M}$ in perfusate). After $10 \mathrm{~min}$, perfusion pressure was measured again - the difference between these pressures reflects the effect of block of NO production on pulmonary vasculature.

\section{NO oxidation products (NOx) concentration} in plasma

Before the embolization, venous blood samples from the left subclavian vein were taken from 11 animals. PE was performed exactly as described in the protocol above, followed by $20 \mathrm{~min}$ stabilization. Subsequently, similar venous blood samples were obtained. They were centrifuged for $3 \mathrm{~min}$ at the speed of $5000 \mathrm{RPM}$ and the acquired plasma was deeply frozen. An NO analyzer was used to analyze NOx (Sun et al. 2010, Hodyc et al. 2012).

\section{Statistical analysis}

All data are shown as mean $\pm \mathrm{SE}$ and analyzed by Statview software with ANOVA or ANOVA repeated measures and Fisher's PLSD posthoc test. Where indicated a paired $\mathrm{t}$ test was used. Differences were considered statistically significant when $\mathrm{p}<0.05$.

\section{Results}

\section{Tempol decreases basal perfusion pressure after PE}

In lungs isolated from rats that had PE (E), the perfusion pressure was significantly higher than in the control group (C). Animals that received Tempol before the embolization (ET) had significantly lower basal pressure than the animals with $\mathrm{PE}$ without a previous Tempol application (E). Basal perfusion pressure did not differ significantly between the control group (C) and animals treated with Tempol (ET) (Fig. 2).

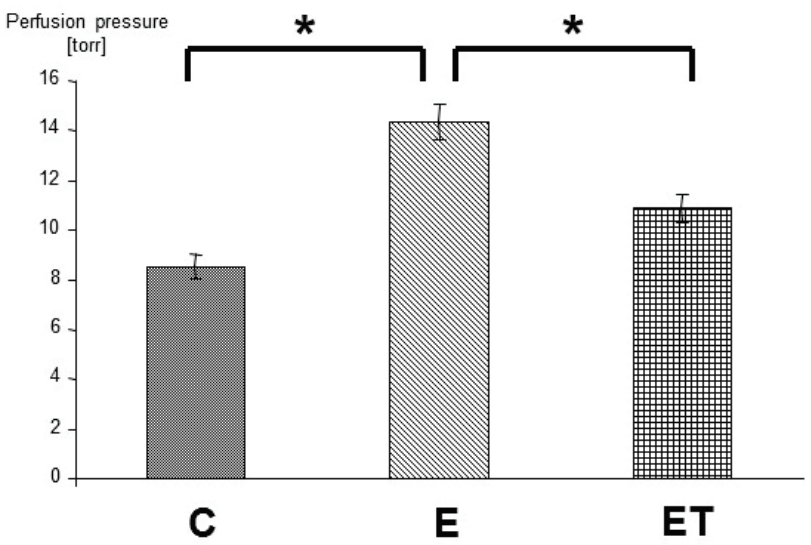

Fig. 2. Tempol decreases basal perfusion pressure after $P E$ $(* \mathrm{p}<0.01)$.

\section{Presence of vasoconstriction}

In the group with PE (EN), we observed a significantly higher decrease in perfusion pressure after application of sodium nitroprusside than in the control group (CN). Vasodilatation induced by nitroprusside in the group with Tempol application (ETN) was similar as in controls (C) (Fig. 3).

\section{Increased activity of $N O$ synthase after $P E$}

Using similar groups as in the previous experiments, the changes of perfusion pressure were measured $10 \mathrm{~min}$ after application of L-NAME. 


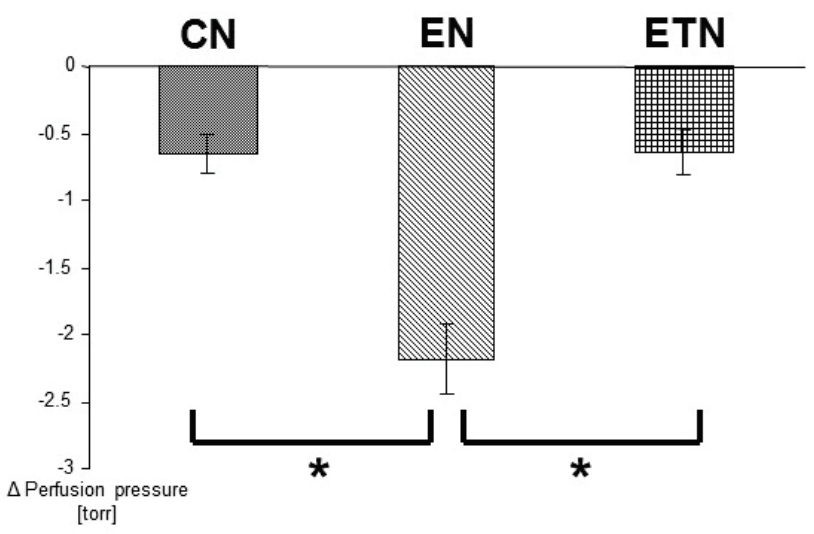

Fig. 3. Effect of sodium nitroprusside on perfusion pressure (higher vasodilatation in EN than in $\mathrm{CN}$ group) illustrates the increase of vasoconstriction after PE $(* p<0.05)$.

Significantly bigger increase in perfusion pressure after L-NAME administration was found in the group which contained PE exposed animals (EL) than in the control group (CL) and in rats that received Tempol prior to the embolization (ETL) (Fig. 4).

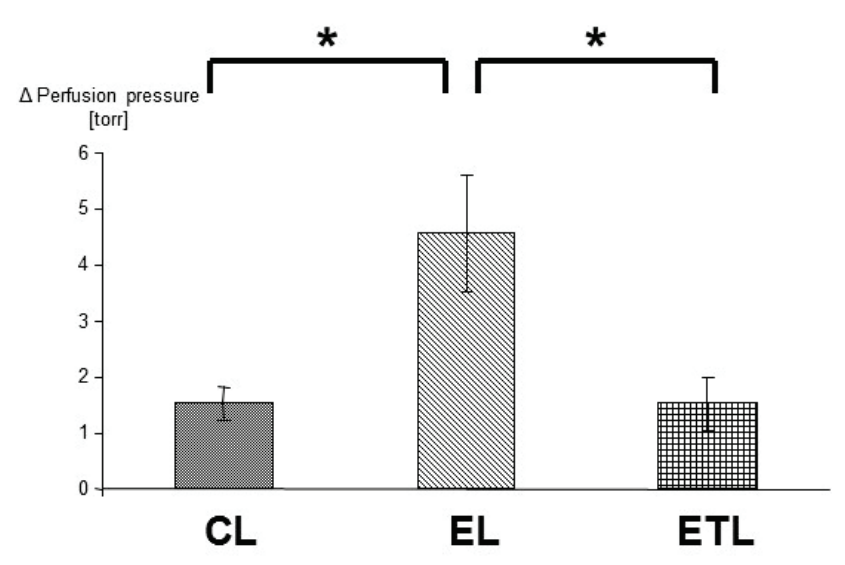

Fig. 4. Higher increase of perfusion pressure after L-NAME administration in rats with $\mathrm{PE}$ (EL) is caused by higher activity of NO synthase after PE $(* p<0.01)$.

\section{Increased concentration of NOx in plasma after PE}

In all the animals with PE, concentration of NOx measured after PE was higher (mean $24.62 \mu \mathrm{M}$ ) than before PE (mean $22.3 \mu \mathrm{M}$ ). The concentration of NOx before and after PE was compared separately for each animal and evaluated by paired t-test.

\section{Discussion}

The main conclusions of our study are the following:
Vasoconstriction which develops after PE is partly caused by an increase of ROS production. After PE, the activity of NO synthase increases and the production of NO rises; application of Tempol lowers the activity of NO synthase.

Our experiment clearly indicates the possible role of ROS in pulmonary hypertension after acute PE, how ROS is generated after PE has not yet been clarified as well as the actual nature of all ROS which cause vasoconstriction of pulmonary vessels.

\section{Possibilities of ROS generation after PE}

All cell elements involved in the process of pulmonary hypertension after PE (thrombocytes, leukocytes, endothelial cells and vascular smooth muscle cells) participate in the production and release of reactive oxygen species during PE. There are four hypothetical ROS generation mechanisms after acute PE: increased shear stress on the wall of pulmonary vessels in the nonembolized part of pulmonary circulation, decreased shear stress in the embolized part behind the embolus, release from activated leukocytes and finally hypoxia.

There is an increase in mechanical pressure on the wall of pulmonary vessels in non-embolized regions of pulmonary circulation by preserved cardiac output. The result of increased shear stress is the upregulation of NAD(P)H oxidase subunit Nox-1, which is found in the cytosol of smooth muscle cells of the pulmonary vessel wall. It also leads to an increase in expression of membrane subunit $\mathrm{p} 47$ phox and its translocation on the smooth muscle cell membrane (Grote 2003). NAD(P)H oxidase produces superoxide. In the regions which have been cut out of the circulation by embolization, the level of the shear stress drops down. This leads to the upregulation of $\mathrm{NAD}(\mathrm{P}) \mathrm{H}$ oxidase and production of superoxide similarly as in the regions with increased shear stress (Fisher et al. 2002). In the smooth muscle cells of non-perfused pulmonary vessels, the intracellular level of $\mathrm{Ca}^{2+}$ rises, which leads to a conversion of xanthine dehydrogenase to xanthine oxidase, which produces ROS (Test et al. 1984, Fisher et al. 2002).

Numerous experimental studies have proven an increase in ROS during hypoxia (Liu 2003). Furthermore, the upregulation of $\mathrm{NAD}(\mathrm{P}) \mathrm{H}$ oxidase is partly responsible for the increase of ROS in hypoxia (Gupte et al. 2005). Another source of ROS in hypoxia is the mitochondrial electron transport chain (Waypa and Schumacker 2005). 
Possible roles of ROS in vasoconstriction after PE

Reactive oxygen species have oxidation potential, they oxidize cysteine and methionine residues of voltage-gated potassium channels and so cause changes in their conformation. Inhibition of these channels leads to the depolarization of cell membranes of smooth muscle cells in the pulmonary vessel wall, which is followed by activation of L-type $\mathrm{Ca}^{2+}$ channels. The next step is $\mathrm{Ca}^{2+}$ ion influx and pulmonary vessel vasoconstriction (Moudgil et al. 2005).

The relationship between ROS and NO plays the key role in the generation of vasoconstriction. Superoxide reacts with NO to form peroxynitrite. This reaction occurs very quickly, four times faster than the reaction of superoxide with superoxide dismutase. The peroxynitrite which is created has a vasoconstrictor effect (Belik 2004).

The second possible pathway of increase in pulmonary vascular tonus after lung microembolism is the $\mathrm{Ca}^{2+}$ sensitization through ROS-dependent activation of RhoA/Rho kinase signaling (Jernigan et al. 2008, Shimokawa and Satoh 2015).

ROS activate matrix metalloproteinases (MMPs) (Grote 2003). MMPs have a significant effect when activated chronically - they induce remodeling of pulmonary vessel walls and finally pulmonary hypertension. After acute PE, activated MMPs are able to break down big endothelin-1 to activated endothelin-1, which has a strong vasoconstrictor potential (Van den Steen et al. 2002, Fernandez-Patron et al. 2001). The preventive application of an MMP inhibitor reduces hemodynamic changes after acute PE (Palei et al. 2005).

\section{Conclusion}

Presented results may help to obtain the insight in the pathogenesis of changes of pulmonary hypertension after the multiple pulmonary microembolism.

\section{Conflict of Interest}

There is no conflict of interest.

\section{Acknowledgements}

The study was supported by GAUK n. 634112/2012, IGA NT 13358-4 and COST Action "EU-ROS” (BM 1203).

\section{References}

BELIK J, JANKOV RP, PAN J, TANSWELL AK: Peroxynitrite inhibits relaxation and induces pulmonary artery muscle contraction in the newborn rat. Free Radic Biol Med 37: 1384-1392, 2004.

DIAS-JUNIOR CA, NETO-NEVES EM, MONTENEGRO MF, TANUS-SANTOS JE: Hemodynamic effects of inducible nitric oxide synthase inhibition combined with sildenafil during acute pulmonary embolism. Nitric Oxide 23: 284-288, 2010.

FERNANDEZ-PATRON C, ZOUKI C, WHITTAL R, CHAN JS, DAVIDGE ST, FILEP JG: Matrix metalloproteinases regulate neutrophil-endothelial cell adhesion through generation of endothelin-1[1-32]. FASEB J 15: 2230-2240, 2001.

FISHER AB, AL-MEHDI AB, MANEVICH Y: Shear stress and endothelial cell activation. Crit Care Med 30 (5 Suppl): S192-S197, 2002.

GROTE K, FLACH I, LUCHTEFELD M, AKIN E, HOLLAND SM, DREXLER H, SCHIEFFER B: Mechanical stretch enhances mRNA expression and proenzyme release of matrix metalloproteinase-2 (MMP-2) via NAD(P)H oxidase-derived reactive oxygen species. Circ Res 92: e80-e86, 2003.

GUPTE SA, KAMINSKI PM, FLOYD B, AGARWAL R, ALI N, AHMAD M, EDWARDS J, WOLIN MS: Cytosolic NADPH may regulate differences in basal Nox oxidase-derived superoxide generation in bovine coronary and pulmonary arteries. Am J Physiol Heart Circ Physiol 288: H13-H21, 2005.

HAMPL V, HERGET J: Perinatal hypoxia increases hypoxic pulmonary vasoconstriction in adult rats recovering from chronic exposure to hypoxia. Am Rev Respir Dis 142: 619-624, 1990.

HERGET J, MCMURTRY IF: Dexamethasone potentiates hypoxic vasoconstriction in salt solution-perfused rat lungs. Am J Physiol 253: H574-H581, 1987.

HERGET J, SUGGETT AJ, PALECEK F, SLAVIK Z: Effect of alpha-methyldopa on lung microembolism in the rat. Bull Eur Physiopathol Respir 18: 687-692, 1982. 
HODYC D, JOHNSON E, SKOUMALOVÁ A, TKACZYK J, MAXOVÁ H, VÍZEK M, HERGET J: Reactive oxygen species production in the early and later stage of chronic ventilatory hypoxia. Physiol Res 61: 145-151, 2012.

JERNIGAN NL, WALKER BR, RESTA TC: Reactive oxygen species mediate RhoA/Rho kinase-induced $\mathrm{Ca}^{2+}$ sensitization in pulmonary vascular smooth muscle following chronic hypoxia. Am J Physiol Lung Cell Mol Physiol 295: L515-L529, 2008.

LIU JQ, SHAM JS, SHIMODA LA, KUPPUSAMY P, SYLVESTER JT: Hypoxic constriction and reactive oxygen species in porcine distal pulmonary arteries. Am J Physiol Lung Cell Mol Physiol 285: L322-L333, 2003.

MOUDGIL R., MICHELAKIS ED, ARCHER SL: Hypoxic pulmonary vasoconstriction. J Appl Physiol 98: 390-403, 2005.

PALEI AC, ZANETI RA, FORTUNA GM, GERLACH RF, TANUS-SANTOS JE: Hemodynamic benefits of matrix metalloproteinase-9 inhibition by doxycycline during experimental acute pulmonary embolism. Angiology 56: 611-617, 2005.

SHIMOKAWA H, SATOH K: Light and dark of reactive oxygen species for vascular function. $J$ Cardiovasc Pharmacol 65: 412-418, 2015.

STRATMANN G, GREGORY GA: Neurogenic and humoral vasoconstriction in acute pulmonary thromboembolism. Anesth Analg 97: 341-354, 2003.

SUN Y, ZHU Z, LANGNAS AN, GRANT WJ, BOTHA JF, ZHAO Y, SUDAN DL, MERCER DF: Plasma nitrite and nitrate levels as a noninvasive marker of pathology after human small bowel transplantation. Transplantation 89: 307-311, 2010.

TANUS-SANTOS JE, MORENO H Jr, MORENO RA, MARTINS ML, PEREIRA R, DE NUCCI G: Inhaled nitric oxide improves hemodynamics during a venous air infusion (VAI) in dogs. Intensive Care Med 25: 983-989, 1999.

TEST ST, LAMPERT MB, OSSANNA PJ, THOENE JG, WEISS SJ: Generation of nitrogen-chlorine oxidants by human phagocytes. $J$ Clin Invest 74: 1341-1349, 1984.

TORBICKI A, PERRIER A, KONSTANTINIDES S, AGNELLI G, GALIÈ N, PRUSZCZYK P, BENGEL F, BRADY AJ, FERREIRA D, JANSSENS U, KLEPETKO W, MAYER E, REMY-JARDIN M, BASSAND JP: Guidelines on the diagnosis and management of acute pulmonary embolism: the Task Force for the Diagnosis and Management of Acute Pulmonary Embolism of the European Society of Cardiology (ESC). Eur Heart $J$ 29: 2276-2315, 2008.

VAN DEN STEEN PE, DUBOIS B, NELISSEN I, RUDD PM, DWEK RA, OPDENAKKER G: Biochemistry and molecular biology of gelatinase B or matrix metalloproteinase-9 (MMP-9). Crit Rev Biochem Mol Biol 37: 375-536, 2002.

WAYPA GB, SCHUMACKER PT: Hypoxic pulmonary vasoconstriction: redox events in oxygen sensing. $J$ Appl Physiol 98: 404-414, 2005. 